Economía Teoría y PrÁctica • Nueva Época, número 47, julio-diciembre 2017, pp. 99-134, http://dx.doi.org/10.24275/ETYPUAM/NE/472017/Gutierrez

\title{
El comercio intraindustrial y los modelos de equilibrio general, parcial y macroeconométrico: del TLCAN a la era de Trump*
}

\section{Intra-Industry Trade and General, Partial and Macroeconometric Equilibrium Models: From nafTa to the Trump Age}

\author{
Roberto Gutiérrez R.**
}

\begin{abstract}
RESUMEN
Aunque suele afirmase que México es más proclive a mirar su pasado que vislumbrar su futuro, a partir de la crisis de 1982-83 se desplegaron esfuerzos para invertir los polos. Un instrumento crucial al respecto fue la puesta en operación, hace casi 25 años, del TLCAN, tomando en cuenta las opiniones de expertos en medición de los niveles de integración sectorial (comercio intraindustrial) y predicción del comportamiento de la economía (modelos de equilibrio general y parcial, así como macroeconométricos). Por una parte, el documento revisa la pertinencia de dichos cálculos, a partir de la misma metodología que los originó y de cuantificaciones expost. Por otra propone que, frente a la opción de retraimiento que ha dejado a los negociadores mexicanos la política comercial del Ejecutivo estadounidense, no sólo se insista en la diversificación y se reconsideren las bondades de la integración a partir del índice de comercio intraindustrial, sino que se continúe con la promoción del mercado interno, reforzando el incremento anual de $9.5 \%$ a los salarios mínimos, decretado en diciembre de 2016.
\end{abstract}

Palabras clave: TLCAN, comercio intraindustrial, crecimiento económico, desarrollo industrial, modelos de equilibrio general y parcial.

Clasificación JEL: F11, F14, F15.

\begin{abstract}
Although it is often said that Mexico is more inclined to look at its past than envision its future, from the 1982-83 crisis efforts were made to reverse the poles. A crucial instrument in this regard was the implementation, almost 25 years ago, of NAFTA, which took into account the opinions of experts in the measurement of the levels of sectoral integration (intraindustrial trade) and prediction of the behavior of the economy (general equilibrium and partial equilibrium models, as well as macroeconometric's). On the one hand, the document examines the relevance of these calculations, based on the same methodology that gave rise to them and on expost quantifications. On the other hand, it proposes that, faced with the option of retreat that has left Mexican trade negotiators the commercial policy of the US Executive, the government should insist not only on diversification and on properly measuring the benefits of integration through the intraindustrial trade index, but to continue the promotion of the domestic market, at least reinforcing the annual increase of $9.5 \%$ to minimum wages, decreed in December 2016.
\end{abstract}

Keywords: NAFTA, Intra-Industry Trade, Economic Growth, Industrial Development, General and Partial Equilibrium Models.

JEL Classification: F11, F14, F15.

*Fecha de recepción: 05/05/2015. Fecha de aprobación: 16/05/2017

${ }^{* *}$ Universidad Autónoma Metropolitana, Unidad Iztapalapa, México. Correo electrónico: robertogtz@yahoo.com.0000-0001-7024-8755 


\section{INTRODUCCIÓN}

A casi dos décadas y media de la puesta en operación del Tratado de Libre Comercio de América del Norte (TLCAN) persisten dudas respecto a la decisión del gobierno mexicano, apoyado por los sectores empresarial y de los trabajadores, de otorgar un alto peso a las estimaciones de que se disponía sobre el comercio intraindustrial (CII) México-Estados Unidos (EU), así como a los resultados que arrojaban los modelos de equilibrio general computable (EGC), equilibrio parcial (EP) y equilibrio macroeconométrico (EM), respecto al comportamiento esperado de la economía, y que sirvieron para avalar la medida. Demostrar esa falta de evidencias y revisar con cifras actualizadas cómo han evolucionado, previa la inauguración de la administración Trump, constituyen los objetivos del presente trabajo.

En materia de CI, las estimaciones de esos años adolecían de varios problemas: se recurría a información muy agregada, las bases de datos de que se disponía no garantizaban una medición muy precisa, y frecuentemente se caía en la tentación de mezclar bases de datos y hacer estimaciones con el fin de llenar huecos o completar series. Por lo que toca a los ejercicios de EGC, EP y EM, aun haciendo a un lado la oportunidad de la información de las matrices de insumo producto (MIP) y variables complementarias, es sintomático que el gobierno de México no haya dudado del optimismo que caracterizaba a los resultados de dichos ejercicios. En general éstos sugerían que prácticamente ningún sector o rama de actividad sería susceptible de sucumbir ante el desmantelamiento arancelario, y que a partir de 1994 la economía crecería a tasas suficientemente altas para generar empleos formales y bien remunerados, además de que progresivamente superaría los desequilibrios que la habían caracterizado desde principios de los años setenta.

La primera sección, Antecedentes, se refiere al contexto en que se llevaron a cabo los ejercicios de medición del CII, el EGC, el EP y el EM, en el marco tanto de la firma del Acuerdo de Libre Comercio Canadá-Estados Unidos (ALCC-EU), del que México fue un espectador, como de las negociaciones y puesta en operación del TLCAN. En la segunda, Estudios sobre CII, se revisan la metodología, las bases de datos y las propuestas de política económica de cuatro trabajos elaborados entre 1991 y 1996, sin dejar de mencionar uno que les antecedió en 1986, abocados exclusiva o parcialmente a la medición del CI México-Estados Unidos, cuya coincidencia fue que el tratado generaría pocos problemas de ajuste a la industria nacional, por lo que algunos explícitamente sugerían obviar el problema o en su caso intensificar la firma de acuerdos de libre comercio con países de otras regiones. En la tercera parte, Resultados a partir de modelos de EGC, EP y EM, se analizan las previsiones de dichos ejercicios con relación al efecto de arrastre del TLCAN en la economía. En la cuarta, Las previsiones y la realidad, se confrontan los resulta- 
dos de las mediciones del CII llevados a cabo hasta mediados de los años noventa con otros más recientes, elaborados con un mayor nivel de desagregación, además de que se hacen consideraciones sobre las diferencias de las cifras macroeconómicas avanzadas por los ejercicios de EGC, EP Y EM y las observadas. En la quinta, Toma de decisiones, se expone cómo, a partir de los resultados anteriores, el gobierno optó por la protección convencional: ofrecer a los sectores que consideró más sensibles un proceso de desgravación gradual y poner en operación, junto con los gobiernos de EU y Canadá, el Banco de Desarrollo de América del Norte (BDAN), cuyo financiamiento a las actividades más afectadas por el tratado ha sido nulo. Esto a diferencia de lo que sucedió en la Comunidad Económica Europea (CEE)/ Unión Europea (UE), donde la condición de socios débiles favoreció el flujo de recursos a Irlanda, Grecia, España y Portugal. En la sexta se hace una revisión expost de las previsiones de los modelos, a la luz de los resultados observados. En la séptima se mencionan los principales problemas del TLCAN que México ya no pedirá se corrijan, dado la nueva política comercial de EU. Finalmente, se presentan las conclusiones.

\section{AnTeCEDentes}

Desde mayo de 1986, cuando iniciaron las negociaciones entre los gobiernos de Canadá y Estados Unidos tendientes a concretar el ALCC-EU, hasta la firma de éste, en octubre de 1987, los responsables de la política económica de México se preguntaron, a la distancia, cuán factible sería para su gobierno lograr algo similar con su principal socio comercial. Los primeros intentos corrieron por cuenta del presidente electo del país, Carlos Salinas de Gortari (1988-1994), quien en una reunión celebrada en noviembre de 1988 en Houston, Texas, con el presidente electo de EU, George Bush (1989-1992), le propuso que sus futuros gobiernos trabajaran en esa dirección.

Después de una serie de pláticas, e incluso de avances sustanciales entre los representantes de los gobiernos de ambas naciones, en junio de 1990 Canadá decidió sumarse a las conversaciones, con objeto sobre todo de cuidar sus intereses; es decir, no verse obligado a ceder, por ausencia, la parte del mercado estadounidense de bienes y los flujos de inversión que estaba ganando con el ALCC-EU. Su decisión hizo que las negociaciones no sólo tuvieran que reanudarse, después de que ya se habían revisado múltiples partidas arancelarias y otros aspectos comerciales y de inversión, sino que se tornaran más complejas, ya que adquirieron un carácter trilateral. Además, al dar lugar a un tratado, su puesta en operación requeriría la aprobación de los congresos de México y EU, así como del parlamento de Canadá. 
La etapa referida a las negociaciones y redacción del documento concluyó el 17 de diciembre de 1992, cuando los presidentes de México y EU, acompañados de sus respectivos secretarios de comercio, y el primer ministro de Canadá, al lado de su ministro de comercio internacional, firmaron el TLCAN. La segunda etapa, llevada a cabo a lo largo del año siguiente, consistió en la discusión y aprobación del documento por parte de los congresos de México y EU, y el parlamento de Canadá. En el proceso surgió un imprevisto: el presidente estadounidense entrante, William Clinton (1993-2000), no manifestó una gran proclividad por el tratado y, habida cuenta de los compromisos adquiridos con algunos grupos durante su campaña electoral, condicionó su aceptación a la negociación y firma de dos acuerdos paralelos, uno laboral y otro ambiental. Su naturaleza fue tal que no implicaron cambios a la legislación interna de ninguno de los tres países, de tal forma que su aprobación por parte de los poderes legislativos se llevó a cabo a fines de 1993, sin mayores fricciones, y el tratado ampliado quedó listo para entrar en operación el $1^{\circ}$ de enero de 1994.

Para cuando esto sucedió, los círculos gubernamentales de México ya tenían indicios sobre los eventuales desequilibrios sectoriales y el impacto macroeconómico del documento acordado. Por una parte, las dependencias más involucradas, particularmente la Secretaría de Comercio y Fomento Industrial (Secofi), habían hecho cálculos internos sobre el grado de integración de las economías de México y EU, poniendo especial énfasis en el cII (Pérez-Motta, 1991). Por otra, promovieron en los centros de investigación el interés por la elaboración de estudios que evaluaran los impactos de carácter microeconómico-comercial y macroeconómico del TLCAN.

En el plano microeconómico-comercial, se condujeron investigaciones abocadas a cuantificar el valor del índice de Grubel y Lloyd (GL) entre México y su principal socio comercial durante los años previos al tratado, a fin de establecer qué parte del comercio bilateral por nivel de actividad era de tipo intraindustrial y de ahí deducir, por complementariedad, el comercio interindustrial. De acuerdo con Linder (1961), el primero se da entre economías con estructuras productivas, patrones de demanda y distribución del ingreso similares, en tanto que el segundo corresponde a la visión tradicional, basada en la dotación de factores que prevé el modelo Heckscher-Ohlin (Ohlin, 1935), también conocido como comercio interindustrial o Norte-Sur, y que corresponde a países con diferente nivel de desarrollo.

La narrativa con que surgió el cII, incluso enfatizada por economistas posteriores a Linder, como Krugman (1988), se refiere a flujos de mercancías de ida y vuelta correspondientes a una misma actividad económica, es decir, a exportaciones e importaciones cuyo destino es el consumo final. Posteriormente se bautizaría a este tipo de flujos como Comercio Intraindustrial Horizontalmente Diferenciado (CIIHD). 
Ethier (1982) y otros hicieron ver que la mayor parte del comercio de dos direcciones se observa en actividades destinadas a la producción, con lo que surgió el término Comercio Intraindustrial Verticalmente Diferenciado (CIIVD). Éste incluye materias primas y bienes elaborados para el procesamiento de productos finales y se observa mucho, aunque no únicamente, en el comercio intraempresa y en las actividades que corresponden a la industria maquiladora de exportación. El alto peso de este tipo de comercio en las relaciones México-EU hizo que durante los años ochenta empezara a ganar relevancia la descomposición del comercio bilateral entre CII y comercio interindustrial. Entre más se conociera esta dicotomía, mayores probabilidades había de determinar si se haría necesaria la aplicación de una política comercial estratégica, entonces en boga (Krugman, 1991b), o si la mejor opción era el autoajuste frente al embate de la competencia externa.

El CII, enmarcado en la presencia de economías de escala y competencia imperfecta, y arropado por la Nueva Teoría del Comercio Internacional (NTCI), era producto de evidencias empíricas acumuladas a lo largo de muchos años en los países desarrollados, sobre todo los miembros de la Organización para la Cooperación y el Desarrollo Económicos (OCDE) y la CEE. De acuerdo con éstas, entre mayor fuera este tipo de flujos comerciales a nivel bilateral, menores serían las afectaciones que se infringirían a las actividades económicas en caso de que los países involucrados negociaran acuerdos de integración comercial. En otros términos, la detección de altos índices de GL en las diferentes actividades económicas previa la puesta en operación de los tratados, permitía presumir que las economías de ambos países se encontraban tan vinculadas que lo único que haría el convenio sería vincularlas más. ${ }^{1}$ En casos como éstos se volvía innecesaria o se minimizaba la necesidad de aplicar programas de ajuste estructural a nivel de sector, industria o rama de actividad, máxime si se consideraba que éstos trastocan el espíritu del libre comercio y absorben recursos susceptibles de destinarse a usos alternativos.

\footnotetext{
${ }^{1}$ Los modelos econométricos abocados a probar los costos del ajuste se basan en la así llamada Hipótesis de Ajuste Suave, o Smooth Adjustment Hypothesis (SAH). Ésta considera que en las ramas con alto CII los costos del ajuste frente a la liberalización comercial son menores o inexistentes respecto a las dominadas por el comercio interindustrial. Normalmente, lo que se toma como variable dependiente o proxi del costo del ajuste es la dinámica del empleo (es factible, aunque engañoso, usar también el número de empresas). Para ello se utilizan datos panel dinámicos que consideran los efectos rezagados de las variaciones del CII marginal (CIIM) en la pérdida de empleos. Se espera que las corridas del conjunto de regresiones generen coeficientes de la variable índice de CIIM con signo negativo y estadísticamente significativos. A partir de ello, el analista tiene elementos para sostener que, entre mayor nivel de CіIM exhiban las ramas de actividad, menores serán los costos que les infrinja el ajuste en términos de plazas de trabajo. Por el contrario, en las ramas en que predomina el comercio interindustrial el costo del ajuste será mayor.
} 
En cuanto al ámbito macroeconómico, el objetivo de los trabajos era conocer, a partir de estudios de EGC, EP y EM con diferentes supuestos de comportamiento, las trayectorias futuras de un grupo reducido de variables agregadas, generalmente producto, empleo, salarios reales y exportaciones. Debe recordarse que los modelos de EGC y los de EM arrojan información sobre los resultados directos e indirectos (secundarios) de la apertura o del fenómeno que se pretende evaluar, en tanto que los modelos de EP y otros métodos ad hoc se preocupan exclusivamente por los resultados directos. Por tanto, para obtener de primera mano variables como flujo de capitales, inversión extranjera directa (IED), ahorro doméstico, saldo de las finanzas públicas e inflación se debe recurrir a modelos de EGC dinámicos (los modelos econométricos a gran escala (MEGE) pueden hacer la labor, pero hay pocos en el mundo). Éstos, a diferencia de los estáticos, que presuponen equilibrio en la cuenta corriente de la balanza de pagos, permiten determinar el comportamiento de variables como tipo de cambio, tasa de interés y formación bruta de capital, sin necesidad de calcularlos exógenamente.

En la medida que las exportaciones a EU y Canadá se aceleraran y crecieran los flujos de capital físico y financiero provenientes de esos países, manifestaba la narrativa de la apertura, se estimularían el crecimiento económico y el empleo. En el corto plazo, empero, se justificaba que la economía sufriera algunos desequilibrios, entre ellos mayor déficit en la balanza comercial, más dependencia del ahorro externo y mayor déficit fiscal. En caso de insuficiencia de recursos para nivelar posibles desequilibrios sectoriales, se tenían grandes expectativas en los recursos que estarían disponibles en el futuro BDAN.

\section{ESTUDIOS SOBRE CII}

El trabajo de Gerardo Esquivel (1992) "Una nota sobre el comercio intraindustrial México-Estados Unidos" es el primero elaborado en México y publicado en una revista científica nacional que se aboca exclusivamente a la medición del CII México-EU; se ha convertido por tanto en una referencia recurrente. ${ }^{2}$ El ejercicio

\footnotetext{
${ }^{2}$ Seis años antes se había dado a conocer en el país un trabajo de Tornell (1986) que en estricto sentido es el pionero de la medición articulada del CI de México con el mundo, incluyendo EU, a pesar de que tiene varias limitaciones metodológicas y analíticas. En primer lugar, lo realiza para un año específico, 1980, y en segundo incluye 100 actividades económicas correspondientes a los dos primeros dígitos (capítulo) de la fracción arancelaria del comercio exterior, reportadas por el entonces Instituto de Estadística, Geografía e Informática (INEGI), lo que implica un nivel excesivamente alto de agregación. Tornell observa que el CII de México con el mundo se ubicó en el año citado en 23 por ciento, y con EU en 26 por ciento. Dado que en términos generales las cifras a ese nivel de agregación reportaban que el cir bilateral del país era más alto con sus socios
} 
es de estática comparada a partir del cálculo de índice de GL, o CII, para los años 1981 y 1990. Esto se hace con una agregación a tres dígitos (grupo) de la Clasificación Uniforme del Comercio Internacional (CUCI), cuya base de datos compila y ordena, a partir de las cifras de cada país, la Organización de las Naciones Unidas (ONU). La justificación que da el autor para trabajar con grupos de productos (150 en 1981; 166 en 1990) es que, en aras de la fidelidad de los resultados, no conviene irse a los extremos: la información muy agregada (sección, un dígito, y capítulo, dos dígitos) sobrestima el valor del índice de GL, mientras la excesivamente desagregada (subgrupo, cuatro dígitos, y partida, cinco dígitos) lo subestima (Esquivel, 1992: 123).

Durante el periodo se observa que el índice de CII total de México con su principal socio comercial se duplicó, al pasar de 27.9 por ciento en 1981 a 54.3 por ciento en 1990. Esto, junto con los cálculos previos de otros autores, particularmente Tornell (1986), a pesar de que no necesariamente se abocaba al CII bilateral México-EU, le hace deducir que en los años previos a su cálculo el CII se había mantenido en permanente ascenso. Al decantar éste a las secciones 5, 6, 7 y 8 de la CUCI, es decir, a los productos manufacturados, su índice de CII bilateral sube de 33 por ciento en 1981 a 62.8 por ciento en 1990. Asimismo, el grupo de productos con el más alto nivel de CII en ambos años es el de manufacturas varias (muebles, prendas de vestir, calzado, artículos fotográficos), el cual además tuvo un aumento espectacular, ya que pasó de 50 por ciento en 1981 a 70 por ciento en 1990. Por su parte, en este último año la participación del comercio de mercancías de ida y vuelta en el comercio total del país, es decir, aquellas en que la mitad de sus flujos comerciales o más son de tipo intraindustrial, fue de 72 por ciento. Al analizar estos resultados, el autor concluye lo siguiente:

La estructura del comercio en 1990 sugiere que el ajuste interno que resulte del proceso de apertura, podría ser mucho menos severo de lo que se esperaría para el caso de países tan distintos como México y Estados Unidos. Esto se debe a que el 72 por ciento del comercio exterior se realiza en productos cuyo comercio es de tipo intraindustrial y que bajo este tipo de comercio, los ajustes esperados en el interior

\footnotetext{
latinoamericanos que con los desarrollados, propuso impulsar las relaciones comerciales con énfasis en la liberalización de las actividades que exhibían mayor CII (política comercial estratégica). Con relación a los países desarrollados, incluyendo EU, sugería que el comercio continuara basándose en la dotación de factores, es decir, que no dejara de ser interindustrial. Es evidente que aún no afloraba la intención del gobierno mexicano de alcanzar un acuerdo comercial con EU; aun así, debían refinarse los cálculos del cII y generar series de tiempo sobre dicha variable a fin de tomar decisiones de política comercial bien sustentadas.
} 
de una economía son menores que en una situación de comercio interindustrial. Además, de los sectores con comercio inter que presentan un déficit en su balanza comercial, sólo algunas empresas productoras de bienes intermedios se verían realmente amenazadas por la apertura ya que el resto podrían dedicarse a nuevas líneas de producción o a una mayor especialización en productos con calidades diferentes (Esquivel, 1992: 135).

El trabajo de Jorge Mattar y Claudia Schatan (1993) "El comercio intraindustrial e intrafirma México-Estados Unidos. Autopartes, electrónicos y petroquímicos" analiza la evolución del CII de México con el mundo y con EU entre 1982 y 1990, para después centrar su atención lo mismo en el cII que en el intrafirma con EU en tres industrias específicas -autopartes; aparatos eléctricos y electromecánicos, con particular referencia a la industria de la computación, y productos petroquímicos-y en dos años específicos, 1982 y 1990. El tratamiento de la información es muy complicado, ya que complementa cálculos sobre cII que proporcionó la Secofi a los autores a tres dígitos de la CUCI con otras cifras calculadas por ellos mismos a partir de la CUCI, en ocasiones no sólo a tres, sino a cuatro dígitos. Adicionalmente, recurren a datos tomados del sistema que maneja el INEGI, tratando de hacerlos compatibles con los de la CUCI, a tres dígitos, y del Sistema Arancelario, a cuatro dígitos. ${ }^{3}$

${ }^{3}$ El texto aclara: "Se usó la CUCI de tres dígitos para el análisis industrial, salvo para la industria de autopartes que parecía demasiado agregada; por tanto, en ese caso se usó la información de cuatro dígitos para algunos sectores. La Secofi proporcionó el índice del comercio intraindustrial correspondiente a 1982 y 1990 para los sectores cuyo comercio representa más de 50 por ciento de dicho intercambio. En cuanto a los sectores de autopartes, eléctrico y electrónico y petroquímico (...), se procesó la información correspondiente a 1980 y 1990 porque es un periodo de comparación más adecuado habida cuenta del ciclo económico. Para la información de 1980 se agregaron los de la CuCi de ocho dígitos del Anuario Estadístico del Comercio Exterior de los Estados Unidos Mexicanos, 1980 del INEGI a la CUCI de tres dígitos. Para traducir la clasificación de la Nomenclatura del Consejo de Cooperación Aduanera a la CuCI, primero se tradujo al Sistema Armonizado, usando el Índice de Correlación de Fracciones Arancelarias de la Tarifa del Impuesto General de Exportaciones e Importaciones, Secofi, vols. 1 y 2, y después la Clasificación Uniforme del Comercio Internacional de las Naciones Unidas, revisión 3 (Informes Estadísticos, Serie M, núm. 34/rev.3, Naciones Unidas, 1986). Con respecto a 1990, se agregó a la CUCI de tres dígitos, con el sistema ya mencionado, la información de cuatro dígitos del Sistema Armonizado proporcionada por la Secofi. La principal fuente de información para 1980 y 1990 es exactamente la misma, pues el INEGI y la Secofi emplean la que la SHCP recaba en las aduanas. Es también la misma para los índices del comercio intraindustrial de 1982 y 1990 proporcionados por la Secofi. Sin embargo, debido a problemas de agregación existe una ligera diferencia entre nuestros índices del comercio 
La justificación que ofrecen para ajustar el nivel de agregación de su investigación a tres dígitos de la $\mathrm{CUCI}$ es la misma que había dado Esquivel: "usar una mayor desagregación, es decir, dividir en varias industrias los productos que pertenecen a una sola, aumenta el riesgo de subestimar el comercio intraindustrial, pues el comercio entre industrias aparentemente diferentes parecerá una actividad comercial interindustrial" (Mattar y Schatan, 1993: 105). En su análisis de resultados observan que:

[...] mientras en 1982 el comercio de apenas 32 sectores de tres dígitos de la CUCI era predominantemente intraindustrial (más de 50 por ciento), en 1990 fueron 86 sectores. [Con relación] al comercio mexicano con Estados Unidos, se aprecia un fenómeno similar, lo que era previsible dada la alta concentración del comercio entre ambos países: de 24 sectores que en 1982 tenían un comercio predominantemente intraindustrial se pasó a 79 en 1990. Para la economía global, el comercio intraindustrial representó 6.1 por ciento del total en 1982 y aumentó a 30.5 por ciento en 1990 (...) En los años ochenta, el comercio intraindustrial entre México y Estados Unidos creció con gran rapidez, pues de representar 6 por ciento del total en 1982, pasó a más de 30 por ciento en 1990. Esto significa que, pese a las grandes diferencias en el desarrollo económico entre ambos países, y al contrario de lo que generalmente predice la teoría convencional del comercio internacional, existen incentivos suficientes para que las compañías de una y otra nación se especialicen en diferentes líneas de producción en la misma industria (Mattar y Schatan, 1993: 108-109 y 123).

Aunque son cautelosos en cuanto a recomendaciones de política económica, ya que condicionan la evolución del sector externo de México a la recuperación económica de EU (antes de la puesta en operación del TLCAN dicho país había estado cerca de una recesión) y al flujo de capitales, en general parecen optimistas con relación a los resultados que podrían derivarse del comportamiento del CII en las tres industrias analizadas.

En su trabajo "El comercio intraindustrial de México con sus principales socios comerciales", Rudolf Buitelaar y Ramón Padilla (1996) cubren los seis años que van de 1990 a 1995. Lo hacen a partir de información a cuatro dígitos del Sistema Armonizado (SA) de Designación y Codificación de Mercancías (SADCM), auspiciado por la Organización Mundial de Aduanas, el cual integra información a dos, cuatro, seis y ocho dígitos. El origen de los datos es la Secofi, responsable de la elaboración de la base SIC-M, la cual usa la Comisión Económica para América Latina y el Caribe (CEPAL) en la preparación de un software muy conocido entre

intraindustrial para los tres sectores seleccionados y los de la Secofi para 1990, aunque se empleó el mismo banco de datos" (Mattar y Schatan, 1993: 106). 
especialistas en comercio internacional y economía industrial, el Módulo para Analizar el Crecimiento del Comercio Internacional (Magic); de éste en realidad proviene la información del estudio. La agregación a cuatro dígitos del sa permitió a Buitelaar y Padilla incluir en el análisis alrededor de 1,250 conceptos o renglones, ocho veces más que Esquivel y 16 por arriba de Mattar y Schatan, aunque las pretensiones del trabajo de éstos eran más acotadas.

Buitelaar y Padilla analizan el cII bilateral de México con sus 33 principales socios comerciales en términos de sus exportaciones y/o importaciones, a excepción de República de Corea, cuya información estadística no se ajustó a sus requerimientos. También presentan el cir con el mundo, aunque su método de trabajo a nivel de agregados podría tener que repetirse, ya que no guarda relación con las partes, problema que se presenta con mucha frecuencia en este tipo de ejercicios y que aparentemente es consecuencia de un mal uso de los ponderadores. Sus resultados muestran que el índice de CII de México con EU en 1995 fue de 43.5 por ciento, el más alto de todos los países que reportan; empero, fue inferior al de 1990, 47.2 por ciento (nótese que al desagregar la información el comercio de México tanto con el mundo como con EU deja de ser preponderantemente intraindustrial).

Sus principales observaciones, a las cuales se puede tomar como sugerencias de política económica, son tres. En primer lugar, a mayor flujo comercial entre dos países, mayor índice de cir; esto querría decir que existe una tendencia natural a que dicho índice aumente con EU y Canadá, lo que disminuye de manera natural los costos del ajuste. En segundo lugar, los acuerdos comerciales bilaterales o multilaterales potencian el cII; por tanto, se refuerza la apreciación de la reducción de los costos del ajuste con EU y Canadá, además por supuesto de las naciones con las que ya se tenían firmados o se estaban negociando tratados de libre comercio: Chile, Costa Rica, triángulo norte de Centroamérica, dupla Venezuela-Colombia, Japón y Unión Europea (debe recordarse que poco después de 1996 México llegó a convertirse en el país que más acuerdos comerciales tenía firmados con el mundo). Y en tercer lugar, a mayor nivel de desarrollo del socio comercial, mayor nivel del CII; esto operaría por tanto a favor del TLCAN y los acuerdos con la Unión Europea y Japón. Complementariamente, el trabajo hace la observación de que, presumiblemente, una parte del CII entre México y EU se debe a la triangulación comercial, por lo que sugieren dar seguimiento a dicha variable.

Aunque el trabajo de Jorge González y Alejandro Vélez "An empirical estimation of intra-industry trade between Mexico and the United States" (González y Vélez, 1991) se escribió en EU y se conoció inclusive antes de que Canadá se incorporara plenamente a las negociaciones que sostenían México y EU para alcanzar un Acuerdo de Libre Comercio (ALC), tiene elementos analíticos destacables 
que los negociadores y los investigadores mexicanos posiblemente no tomaron en cuenta en ese momento pero que, de haber incorporado, les habrían sido de utilidad.

El estudio se refiere al CI entre México y EU en el periodo 1982-1990. La base de datos con que elaboran sus cálculos es la CUCI a dos niveles de desagregación: tres y cuatro dígitos. Esto quiere decir que se trata del primer trabajo que, entre otras cosas, logra mostrar la trascendencia de la agregación en las cifras del CII bilateral. Así, a tres dígitos el CII México-EU pasa de 35.7 en 1982 a 58.1 por ciento en 1990 , y a cuatro dígitos sube de 23.2 a 46.1 por ciento. Si el análisis a tres dígitos se circunscribe a la industria manufacturera, pasa de 38.6 en 1982 a 62.8 por ciento en 1990 , y con cuatro dígitos sube de 26.6 a 51.6 por ciento.

Por tanto, el documento muestra que en 1990 el comercio bilateral total México-EU a cuatro dígitos de la CUCI no fue preponderantemente intraindustrial, y sólo llegó a serlo cuando se le circunscribió a las actividades de la industria manufacturera.

La principal conclusión de política comercial apuntada por González y Vélez, y que después retoman en otras investigaciones en que incluyen el cir bilateral de EU con un número considerable de países de América Latina, es que siendo tan alto el grado de integración de la economía mexicana a la de EU, su proceso de ajuste debería resultar menos difícil que el del resto de países de la región.

\section{Resultados A PARTIR DE MODElOS DE EGC, EP Y EM}

A principios de la década de los años noventa académicos de México y EU llevaron a cabo un número considerable de ejercicios de EGC, EP y EM con objeto de cuantificar los efectos macroeconómicos y/o sectoriales de la eventual firma ya fuera de un ALC México-EU o de un TLCAN, en cuyo caso se incluiría a Canadá.

Para fines de este recuento, dos publicaciones destacaron por presentar y analizar, de manera comparativa, los resultados de estos trabajos, con especial énfasis en sus capacidades y debilidades predictivas así como sus consecuencias para el desarrollo de la región. El primero fue resultado de un encuentro de expertos llevado a cabo en abril de 1992 en la Brookings Institution de EU, contando con el auspicio de la Fundación Ford, compendiado y comentado por Lustig, Bosworth y Lawrence (1992). En él se comparan los resultados de varios ejercicios de EGC, EP y EM, con tendencia a privilegiar los elementos cualitativos. El segundo es un compendio del Departamento del Trabajo de EU que "...hace un resumen de las implicaciones del TLCAN para la economía de EU y sus trabajadores, a partir de la revisión de más de dos docenas de diferentes estudios de impacto conducidos por individuos, organizaciones privadas y agencias gubernamentales" (DOL, 1993: 1). 
En éste, lo que prevalece son los aspectos cuantitativos. Por tanto, se trata de dos trabajos complementarios. ${ }^{4}$

Ambos documentos muestran una enorme preocupación respecto a las consecuencias de lo que sería la primera experiencia mundial de integración entre dos países colindantes con niveles de desarrollo altamente dispares. A partir de esto, notan que los trabajos reseñados predicen que el TLCAN conducirá a una serie de resultados favorables no sólo para México y EU, sino también para Canadá, aunque reconocen que los impactos serán diferentes.

El resumen de la Brookings Institution observa que la liberalización comercial y de inversiones que propiciaría el TLCAN conduciría a:

- Un crecimiento importante del comercio exterior, no obstante que los aranceles ya habían empezado a bajar y se había suprimido una parte importante de las restricciones cuantitativas.

- Modificaciones limitadas en materia de precios relativos lo que implicaría, entre otras cosas, pocos cambios en las demandas relativas de los productos y mínimas presiones en los índices comparados de precios al consumidor y al productor.

- Un mayor flujo de capital a México.

- Un impulso moderado al crecimiento económico de Canadá y EU, pero mayor en el caso de México, lo que permitiría mejorar las condiciones de vida del país.

- Un aumento en el déficit comercial de México a favor principalmente de EU, nación con la que llevaba a cabo el 70 por ciento de su comercio exterior.

- Aunque el efecto neto en términos de los salarios reales de los trabajadores de EU sería positivo, los más calificados experimentarían beneficios que se verían contrarrestados parcialmente por pérdidas para los menos calificados.

- En contraste, los trabajadores mexicanos menos calificados experimentarían alzas reales de sus salarios, con posibles efectos para los más calificados.

- Debido a que los salarios reales promedio de ambos países aumentarían, éstos mantendrían la trayectoria de divergencia que los había caracterizado (aproximadamente de 10 a 1), atribuida al mayor desarrollo y productividad de la mano de obra estadounidense.

\footnotetext{
${ }^{4}$ Además, la United States International Trade Comission de EU compendió un amplio número de trabajos abocados a evaluar los efectos de un acuerdo bilateral o trilateral, con énfasis en los impactos en la economía estadounidense (USITC, 1992). Asimismo, en México varios investigadores dieron a conocer, con la aprobación de la Secofi, un resumen del efecto que esperaban tuviera el TLCAN en la economía a partir de varios trabajos de EGC, EP y EM (García, Kehoe, Romero y Sobarzo, 1991).
} 
- Se detectaba que los trabajadores del campo mexicano productores de maíz se verían perjudicados debido a un aumento de las importaciones, mientras que los productores estadounidenses resultarían beneficiados.

- Empero, una válvula de escape fundamental sería la migración interna, que presionaría hacia una mayor urbanización, sustentada entre otras en la dinámica de la industria de la construcción.

- Una segunda válvula de escape, particularmente enfatizada por los investigadores estadounidenses, sería la migración externa, que podría llegar hasta 600 mil trabajadores, sobre todo provenientes del campo.

- Lo mismo para el caso de la migración interna que de la externa, los salarios de los sectores receptores tenderían a disminuir.

- Los únicos productores del campo mexicano que se beneficiarían con el tratado serían los de frutas y legumbres del norte del país y, dentro de las industrias manufactureras, seguramente lograrían una mejor situación los de vestido, piel, vidrio y posiblemente maquinaria eléctrica.

- Los estudios sugerían que las industrias mexicanas que resultarían más afectadas serían la química, de equipo de capital, de acero, electrónica y de artículos de hule y plástico.

- En cuanto al factor capital, se estimaba que los rendimientos de éste aumentarían en México, sin que ello provocara una escasez preocupante en EU, dada su amplia dotación de dicho factor.

Por su parte, el documento del Departamento del Trabajo de EU resumió así los resultados de los estudios analizados:

Casi todos los estudios de impacto indican que el TLCAN hará que aumenten el producto real y los salarios y/o el empleo de EU, no obstante que las magnitudes en general son bajas y muestran variaciones considerables entre las ramas industriales y las áreas geográficas. La comparación de los diferentes estudios de impacto permite observar que:

1) a pesar de que hay diferencias en cuanto a la modelación, la cobertura, los métodos y los resultados, las estimaciones son muy similares con respecto a la magnitud y dirección de los cambios dentro de los próximos 5-10 años;

2) los efectos estimados para la economía de EU tienden a ser más evidentes en los estudios que consideran economías de escala, mercados de competencia imperfecta y una eliminación considerable de las barreras no arancelarias; 
3) los estudios que explícitamente incluyen la migración internacional llegan a resultados que pueden diferir de los que no lo hacen, especialmente debido a sus efectos en los ingresos y los salarios, y

4) no obstante que en sus agregados se espera que suban el empleo y/o los salarios reales, el principal efecto del TLCAN en el empleo de EU parece observarse en la composición del sector industrial y no en su nivel (DOL, 1993: i).

Complementariamente, habría que destacar que una de las corridas del estudio de EGC elaborado por Sobarzo (1991), partiendo de los supuestos de tipo de cambio flexible, salarios fijos y economías de escala -escenario que expost se ubica como el más cercano a lo que sucedió a partir de 1995-, predijo el siguiente comportamiento sectorial en materia de crecimiento del producto bruto y el empleo:

- Las más altas tasas de crecimiento del producto bruto (arriba de 5 por ciento, promedio anual) y de generación de empleos (entre 9 y 10 por ciento promedio anual), se registrarían en los sectores de maquinaria eléctrica y equipo de transporte.

- En segundo lugar aparecen aquellos con un crecimiento esperado del producto bruto de entre 3 y 4 por ciento y del empleo entre 7 y 9 por ciento: otras manufacturas, hierro y acero, maquinaria no eléctrica, prendas de vestir y textiles.

- Les siguen las que avanzarían a un ritmo de crecimiento de entre 2 y 2.9 por ciento y generarían empleos a una tasa de entre 4 y 8 por ciento: cuero, madera, papel, química, hule, tabaco, alimentos, bebidas, minerales no metálicos, metales no ferrosos, productos metálicos y construcción.

- En cuarto aparecen las que se expandirían a ritmos más lentos tanto en su producto (entre 1.2 y 1.9 por ciento) como en su empleo (entre 5.5 y 6.5 por ciento): minería, electricidad, comercio, transporte y servicios financieros.

- Sólo dos industrias, petróleo y otros servicios, se estancarían en términos de su producto, y su generación de empleos sería de entre 0 y 2.9 por ciento.

- Las cifras anteriores conducen, en promedio, a una elasticidad producto del empleo de 2.6, que se explica particularmente por la alta dinámica que la estimación de Sobarzo atribuye a las exportaciones de manufacturas (las tasas de crecimiento de éstas van desde 8.5, en el caso de alimentos, hasta 59.4 por ciento, en el de prendas de vestir.

Los documentos reseñados omitieron mencionar los costos de transición que se esperaba enfrentaran algunos sectores de la economía mexicana, la cual proporcionalmente resentiría más el TLCAN, aunque también sería la más beneficiada. 
Y cuando se referían a EU consideraban que, por su tamaño, en caso de que se materializara cierta vulnerabilidad en algunos sectores, el problema sería perfectamente asimilable. Además, consideraban que el banco de desarrollo regional que se estaba gestando tendría un papel tan decisivo como el que había tenido el Banco Europeo de Inversiones (BEI) en la convergencia de las economías europeas. En particular, es de recordarse su importancia en el proceso de inserción de Irlanda (1973), Grecia (1981), y España y Portugal (1986) a la entonces CEE. Este financiamiento, junto con la eliminación de trabas al comercio y al flujo de factores productivos, permitió que a partir de 1991, cuando la CEE dio paso a la UE, y hasta 2000, año previo a la primera recesión del nuevo siglo, las tasas de crecimiento per cápita de los cuatro países aumentaran muy por arriba del promedio del resto.

\section{LAS PREVISIONES Y LA REALIDAD}

\section{Comercio intraindustrial (CII)}

Al confrontar los resultados de las mediciones del CII llevados a cabo durante los años previos a la puesta en operación del TLCAN, en general a tres dígitos de la $\mathrm{CUCI}$, con los que se han realizado durante el siglo XXI, casi todos a cinco dígitos de la CUCI o su equivalente en SA, se observan diferencias notables, ya que los primeros estimaban índices de ci promedio de más de 50 por ciento total y de más de 60 por ciento manufacturero, en tanto los segundos llegan a cifras promedio alrededor de 40 por ciento en ambos casos, con un estrechamiento notable de la diferencia entre el total y el manufacturero (cuadro 1).

Dado que el cI implica ventajas comparativas adquiridas (dinámicas), a diferencia del comercio tradicional o Hecksher-Ohlin (Ohlin, 1935), que se basa en ventajas comparativas estáticas, los resultados anteriores sugieren una regresión considerable a partir de inicios del siglo xx, es decir, un proceso de desarticulación industrial. En otros términos, el descenso del índice GL parece ser un reflejo de la desindustrialización del país, que se originó a partir del momento en que éste optó por ser fiel a una tradición que había tratado de superar durante el periodo de industrialización vía sustitución de importaciones: concentración de esfuerzos productivos en sectores intensivos en mano de obra de baja especialización, dejando a sus principales socios comerciales los intensivos en mano de obra calificada.

El patrón anterior se observa en muchas industrias, entre ellas la petrolera y la químico-petroquímica: con la idea de aprovechar las economías de escala de la región del TLCAN, a partir por lo menos de la instauración de la Alianza para la Seguridad y Prosperidad de América del Norte (ASPAN), en 2005, como 
114 ECONOMÍA TEORÍA Y PRÁCTICA • Nueva Época, número 47, julio-diciembre 2017

Cuadro 1. cll bilateral México-Eu con diferentes niveles de agregación, periodos y cobertura (\%)

\begin{tabular}{|c|c|c|c|c|}
\hline ESTUDIO & AGREGACIÓN & ÚLTIMO AÑO & ICI TOTAL & ICII MANUFACTURERO \\
\hline Esquivel (1992) & CUCI 3 Dig. & 1990 & 54.3 & 62.8 \\
\hline Mattar/Shatan (1993) & CUCI 3 Dig. & 1990 & $30.5^{*}$ & $42.7^{*}$ \\
\hline Buitelaar/Padilla (1996) & SA 4 Dig. & 1995 & 43.5 & - \\
\hline GonzálezNélez (1991) & CUCI 3 Dig. & 1990 & 58.1 & 62.8 \\
\hline González/Nélez (1991) & CuCl 4 Dig. & 1990 & 46.1 & 51.6 \\
\hline Brülhart (1996) & Cucl 3 Dig. & 1998 & 56 & 61 \\
\hline Clark/Fullerton/Burdorf (2001) & CuCl 2 Dig. & 1998 & & 63 \\
\hline Promedio & & & 51.6 & 60.2 \\
\hline Gutiérrez, R. (2012) & CUCI 5 Dig. & 2005 & & 42.1 \\
\hline Sotomayor (2009) & $\begin{array}{l}\text { SA } 8 \text { Dig./CIIU } 6 \\
\text { Dig }\end{array}$ & 2006 & 39.8 & $38.8^{* *}$ \\
\hline ALADI (2012) & NE & 2010 & 39.7 & - \\
\hline Promedio & & & 39.75 & 38.8 \\
\hline
\end{tabular}

*Manuf = Promedio autopartes, computadoras y productos químicos. Por tratarse de sólo tres industrias, estos valores no se toman en cuenta para el promedio.

**Industria maquiladora de exportación.

ne: no especificado.

resultado precisamente de las reuniones trilaterales, México concentró sus capacidades en la producción y las exportaciones de petróleo crudo, y optó por depender de las importaciones de productos petrolíferos y gas, ya que el asociado al crudo sólo lo recupera parcialmente. En paralelo, siguió exportando algunos productos de bajo valor agregado, como combustóleo, azufre y amoniaco, y otros más complejos, pero a lo sumo intermedios, como el etileno, ya que su utilización interna fue deficiente hasta 2015 debido a la mala integración de las cadenas productivas en la industria químico-petroquímica.

Sobre esta base, y dado que EU dispone de 149 refinerías de petróleo, el gobierno de México optó por no construir ninguna (la última, Antonio Dovalí Jaime, en Salina Cruz, data de 1979) y sólo se concentró en la reconfiguración de tres existentes, Cadereyta, Ciudad Madero y Minatitlán, sin que esto se tradujera en un aumento de la capacidad de procesamiento. Paralelamente, gobierno e iniciativa privada decidieron no invertir en nuevas instalaciones para la industria químico-petroquímica (las últimas datan de mediados de los años ochenta) y es- 
peraron hasta la segunda década del siglo xxi para que, con apoyo del capital internacional, se iniciara la construcción de la planta Etileno XXI (sustitución del fallido proyecto El Fénix), la cual entró en operación a mediados de 2016.

Estas decisiones hicieron que el país se convirtiera en un fuerte importador de gasolinas, diesel, gas natural licuado, gas seco, fertilizantes nitrogenados, urea, toluenos, xilenos, artículos de plástico, caucho, químicos orgánicos, cosméticos, resinas sintéticas, fibras, jabones, detergentes, pinturas, etcétera. Las importaciones conjuntas de dichos productos pasaron de 27,800 millones de dólares en 2002 a 86,900 millones en 2012 (Pemex, 2013; INEGI, 2008 y 2013). Es decir que, por decisión propia, México fue regresando en varios sectores a un patrón predominantemente de comercio interindustrial, tipo Heckscher-Ohlin (1935).

Lo anterior explica mucho del comportamiento de la gráfica 1, en que se muestra que el CII manufacturero (CIIM) bilateral México-EU, medido en lapsos quinquenales a partir de 1980 con la base de datos más actualizada, alcanzó su punto máximo en 2000, apenas seis años después de la puesta en operación del tratado, con una tendencia creciente a partir de 1980 (la medición es a cinco dígitos de la CuCı revisión 4). A partir de ese año inició un descenso leve, hasta ubicarse en 46.3 en 2015. El cambio de tendencia fue en contra de todas las expectativas del TLCAN y se explica por las recesiones de 2001 y 2008-2009, que tienen efectos particularmente perniciosos en el comercio. Incluso se observa que existe una relación positiva entre el comercio total y el CIIM (Gutiérrez R., 2012). El hecho de que en 2015 apenas haya logrado restablecerse el nivel de CI que se tenía con el TLCAN en 2000, sugiere que las capacidades de éste para promover el desarrollo industrial de México vía la integración entre industrias con aquellos países permanecerán débiles. Para superar el bache se requeriría que las autoridades comerciales de ambos países se pusieran de acuerdo en una renovación del espíritu del tratado, volcándose hacia la integración regional para detener el embate de otros competidores, particularmente los asiáticos, algo que evidentemente será muy difícil en el corto plazo, dada la política comercial del presidente Trump y las tendencias a la cerrazón comercial de otros países desarrollados.

Dado que el CII puede surgir simplemente por la forma en que se registran y analizan los datos de las transacciones comerciales, el grado de agregación es fundamental. Si la categoría es amplia, por ejemplo "bebidas y tabaco", bien podría registrarse cII. Pero al separarla en "bebidas" y "tabaco", lo más seguro es que dicho CII no sólo disminuya, sino que incluso llegue a desaparecer en una de las dos subcategorías. A pesar de que había conciencia al respecto, desde el surgimiento de la medición del CII mediante el índice de GL hasta fines del siglo XX se trabajó con niveles de agregación muy altos: dos y tres dígitos de la CUCI (Grubel y Lloyd, 1975; Stone y Lee, 1995; OCDE, 2002). 


\section{Grafica 1. Índice de comercio intraindustrial México-EU (\%)}

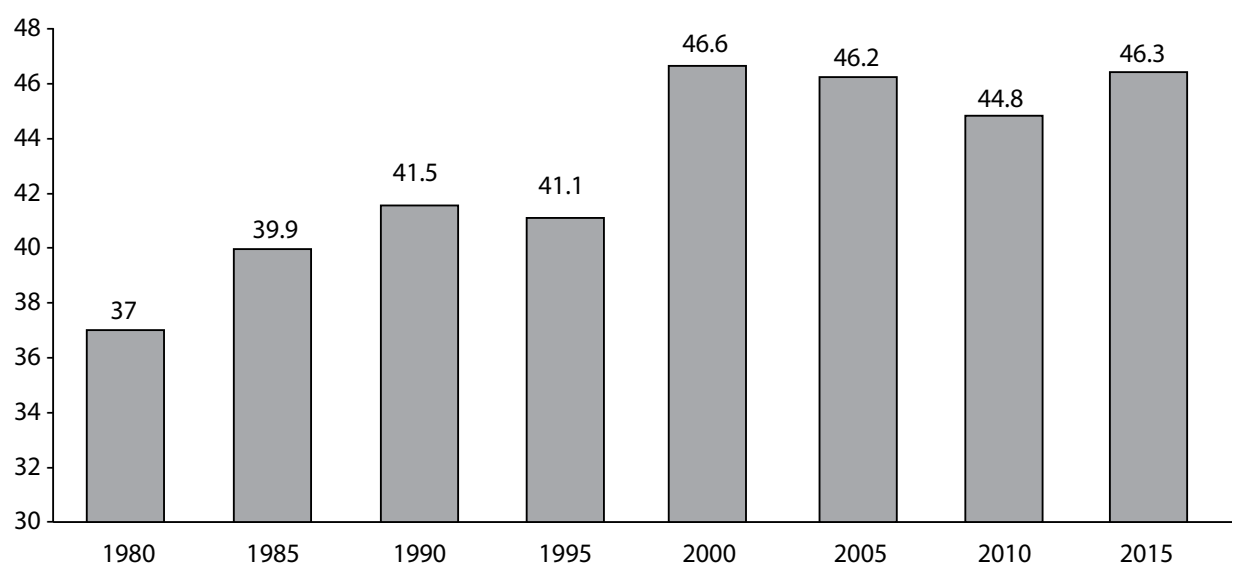

Fuente: Cálculos propios elaborados a partir de wits (2016), con cucı Rev. 4.

Posteriormente se asimiló que la desagregación conducía a una mayor exactitud y a mejores decisiones de política económica, además de que sólo contando con información desglosada era posible calcular el CIIHD, el CIIVD, y a su vez dividir éste en CII de baja calidad (CIIVDBC) y de alta calidad (CIIVDAC). Ambos se refieren al ámbito de la producción, sólo que el primero considera bienes con calidades diferentes que se reflejan en precios dispares dentro de una misma categoría, lo cual corresponde en mucho al CII Norte-Sur (es el caso del CII México-TLCAN), en tanto el segundo se refiere a artículos muy parecidos en calidad y tiende a observarse más en el CII Norte-Norte (por ejemplo, países del norte de Europa). Por tanto, los análisis incorporaron desgloses de hasta cinco dígitos de la CUCI, y sus equivalentes en SA y Clasificación Industrial Internacional Uniforme (CIIU). Esto evidentemente implicó operar bases de datos en CUCI de entre 2,000 y 2,500 partidas (Gutiérrez R., 2012 y cálculos de la gráfica 1) y en ciIU de hasta 310 renglones (Sotomayor, 2009).

\section{Modelos de EGC, EP y EM}

Si se miden los impactos esperados del TLCAN en un plazo de 22 años, se observa que en general los estudios en que se basa el análisis comparativo del Departamento del Trabajo de EU fueron excesivamente optimistas, ya que el consenso sugería (aunque la dispersión tendía a ser muy alta) que los salarios reales de México cre- 
cerían a una tasa promedio de 7.5 por ciento, el empleo agregado formal aumentaría a un ritmo anual de 3.3 por ciento, el PIB real se expandería a una tasa de 5.7 por ciento, el ingreso nacional lo haría al 2.5 por ciento y las exportaciones a EU crecerían 9.4 por ciento en promedio, como se observa en el cuadro 2 .

De las cifras mencionadas, la única que después de 22 años estuvo cercana al consenso fue la de exportaciones a EU, aunque al deflactarla con el Deflactor Implícito de Precios de Importaciones de EU se queda corta en -1.2 por ciento. Los casos más dramáticos son los salarios reales, que se rezagaron -11.2 por ciento de la meta, y el PIB, que lo hizo -3.2 por ciento. Esto último quiere decir que, mientras las expectativas de los modelos eran que el producto del país se duplicara en 2005 y se triplicaría en 2016, al ritmo en que está creciendo se duplicará en 2021 y triplicará en 2029. Por tanto, en vez de acercarse a las economías emergentes, con las que compite en los mercados internacionales de productos y capitales, en realidad se está alejando.

Cuadro 2. Efectos del TLCAN esperados promedio de diferentes estudios vs. observados: 1993 a 2015 Tasas medias de crecimiento (\%)

\begin{tabular}{|l|c|c|c|}
\hline \multicolumn{1}{|c|}{ CONCEPTO } & ESPERADOS* & $\begin{array}{c}\text { OBSERVADOS } \\
(1993-2015)\end{array}$ & DIFERENCIA \\
\hline Salarios reales (1) & 7.5 & -3.7 & -11.2 \\
\hline Empleo remunerado (2) & 3.3 & 1.0 & -2.3 \\
\hline PIB real & 5.7 & 2.5 & -3.2 \\
\hline Ingreso nacional real (3) & 2.5 & 0.1 & -2.4 \\
\hline Exportaciones a EU (4) & 9.4 & 8.2 & -1.2 \\
\hline
\end{tabular}

*Promedio de las proyecciones para cada renglón.

(1) Salario mínimo promedio nacional a precios constantes.

(2) Trabajadores asalariados remunerados.

(3) Ingreso nacional bruto menos consumo de capital fijo menos agotamiento de recursos naturales.

(4) Precios deflactados con el índice de importaciones de EU.

Fuentes: Con base en DOL (1993: 58) para valores esperados, y Bureau of Labor Statistics (BEA) (2016), INEGI (2016), Secretaría del trabajo y Previsión Social (STPS) (2016) y Banco Mundial (2016), para valores observados.

Otro punto a resaltar es que, al haber estado tan cerca las cifras estimadas de las observadas en materia de exportaciones, las fallas de los modelos deben enfocarse no en la capacidad del TLCAN para promover el comercio de mercancías en los países signatarios, sino en la elasticidad de los salarios reales, el empleo remunerado, el PIB y el ingreso reales con relación a las exportaciones. Y si esta elasticidad no se dio en el periodo 1994-2015, menos se observará en la era Trump. 


\section{TOMA DE DECISIONES}

A partir de los resultados que se obtuvieron entre 1990 y 1993 con la medición del CII y los ejercicios de EG, EP y EM, en gran medida estimulados por el gobierno federal, éste contando con el apoyo empresarial y de los trabajadores tomó dos decisiones trascendentales: optó por no brindar protección a ningún sector de la economía, excepto por el apoyo convencional de negociar con EU y Canadá el mayor alargamiento posible del periodo de desgravación arancelaria para una serie de ramas, y se confió en los beneficios que podría ofrecer el BDAN, una vez que lo pusieran en operación los gobiernos de los tres países signatarios del tratado.

La medida de apoyo arancelario consistió en consolidar hasta 15 años después de iniciado el tratado (fecha que se cumplió el 31 de diciembre de 2008) la desgravación total de tres productos agrícolas considerados muy sensibles: maíz, frijol y leche en polvo. Para 10 años (hasta el 31 de diciembre de 2003) se dejó la desgravación total de automóviles nuevos y usados con al menos 10 años de antigüedad, así como la mayor parte de productos textiles y algunos otros. Y a cinco años (hasta el 31 de diciembre de 1998) se estableció la desgravación de la mayor parte de los camiones pesados y ligeros, los tractocamiones, los autobuses $\mathrm{y}$ algunos otros productos. El resto se desgravó a partir de la puesta en operación del TLCAN; y para muchos de los que tenían desgravación calendarizada, se convino sobre la marcha en adelantar los plazos.

Los cálculos sobre CII fueron particularmente consecuentes con las medidas arancelarias previamente consignadas, ya que por una parte estimaban que más de la mitad del comercio bilateral era de tipo intraindustrial, y que éste se manifestaba mayoritariamente en el sector manufacturero, donde antes de esos estudios se temía que fuera necesario aplicar esquemas de ajuste, debido a la escasa integración de industrias similares a ambos lados de la frontera. Incluso Esquivel aseguraba que en 72 por ciento de las actividades económicas de México predominaba el CII (exhibían índices de CII superiores a 50 por ciento), y aclaraba que el grupo de productos con el más alto nivel era el de manufacturas varias (muebles, prendas de vestir, calzado, artículos fotográficos), el cual además tuvo un salto espectacular al pasar su índice de CII de 50 en 1981 a 70 por ciento en 1990.

Las mediciones posteriores mostrarían que el CII no había sido tan alto a principios de los años noventa como se estimó originalmente; que a finales de la primera década del siglo XXI éste se ubicaba en alrededor de 45 por ciento, tanto a nivel global como en el sector manufacturero, y que entre 2000 y 2010 se había observado un descenso continuo de dicha variable, lo que sugería que el TLCAN se estaba acercando al agotamiento en cuanto a su capacidad para promover la industrialización del país. Esto en virtud de la desarticulación de varias industrias 
nacionales con sus pares de EU, lo que en combinación con las dificultades de promover acciones más favorables para la industria del país impone la necesidad de impulsar nuevos mecanismos de apoyo al crecimiento económico y a la generación de empleos.

Más aún, varias de las industrias que autores como Esquivel, Mattar, Schatan y Sobarzo visualizaron a principios de los años noventa como posibles ganadoras de la apertura comercial, en gran medida no pasaron la prueba del tiempo, como tampoco sucedió con el sector manufacturero en su conjunto, en el que todo el país tenía cifradas sus esperanzas, dada la baja productividad de los sectores primario y terciario, que finalmente terminó arrastrándolos. Por lo menos así se reconoce oficialmente en el Programa para Democratizar la Productividad 2013-2018 (DOF, 2013).

El cuadro 3 muestra que entre el año pico del empleo manufacturero remunerado posterior al inicio del TLCAN, 2003, y el año de recuperación plena del comercio después de la gran recesión de 2008-2009, que fue 2011, el número de puestos de trabajo disminuyó en 691,765 , lo que representó un descenso de -13.73 por ciento. Todos los componentes que se presentan en el cuadro, a excepción de la industria de fabricación de maquinaria y equipo (10.01 por ciento), exhibieron descensos, incluyendo por supuesto la industria textil en su conjunto (-38.05 por ciento), con especial referencia en la de prendas de vestir (-39.07 por ciento); la industria química (-23.52 por ciento); muebles y productos relacionados (-20.95 por ciento); computadoras y productos electrónicos (-18.61 por ciento); plástico y hule (-18.51 por ciento); productos de generación eléctrica y accesorios (-16.05 por ciento); equipo de transporte (-15.67 por ciento), no obstante la posición vanguardista de México en la producción y exportación de autos y autopartes, y otras industrias manufactureras ( -4.60 por ciento).

La segunda medida, consistente en la puesta en operación del BDAN, nació desvirtuada, ya que se orientó desde un principio al financiamiento de proyectos de infraestructura en los estados fronterizos de México y EU, como muestra la gráfica 2, sin ofrecer apoyo a los sectores afectados por el TLCAN, como originalmente se esperaba. La alternativa de EU frente a esa omisión fue aprovechar un programa interno del gobierno federal, que existía desde los años sesenta del siglo XX, conocido como Trade Adjustment Assistance (TAA), con el que se brinda apoyo a los trabajadores y productores de diversos sectores de la economía que resultan afectados debido a la competencia de las importaciones. Entre 1994 y 2002 el número de trabajadores beneficiados en virtud de haber perdido su empleo por la puesta en operación del TLCAN fue de 525 mil, un promedio de 58 mil por año (Feenstra y Taylor, 2011: 207). 
120 ECONOMÍA TEORÍA Y PRÁCTICA • Nueva Época, número 47, julio-diciembre 2017

CUADRO 3. Puestos de trabajo remunerados en el sector manufacturero por industria 1998-2011

\begin{tabular}{|c|c|c|c|c|c|c|c|}
\hline CONCEPTO & 1993 & 1998 & 2003 & 2007 & 2011 & $\begin{array}{c}\text { DIF. } \\
\text { 2001-1998 }\end{array}$ & $\begin{array}{c}\text { \% SOBRE } \\
2003\end{array}$ \\
\hline TOTAL & 3310000 & 3373206 & 5036836 & 4973271 & 4345071 & -691765 & -13.73 \\
\hline Industria textil & & 657228 & 590823 & 490560 & 366000 & -224823 & -38.05 \\
\hline Insumos textiles & & & 104000 & 89758 & 67209 & -36791 & -35.38 \\
\hline $\begin{array}{l}\text { Confección de produc- } \\
\text { tos textiles excepto pren- } \\
\text { das de vestir }\end{array}$ & & & 51244 & 49323 & 33373 & -17871 & -34.87 \\
\hline $\begin{array}{l}\text { Fabricación de prendas } \\
\text { de vestir }\end{array}$ & & & 435579 & 351479 & 265418 & -170161 & -39.07 \\
\hline $\begin{array}{l}\text { Fabricación de productos } \\
\text { de cuero excepto pren- } \\
\text { das de vestir }\end{array}$ & & & 163644 & 158572 & 146472 & -17172 & -10.49 \\
\hline Industria de la madera & & 164165 & 130137 & 125619 & 110829 & -19308 & -14.84 \\
\hline Industria del papel & & 182052 & 111271 & 100806 & 94097 & -17174 & -15.43 \\
\hline Industria química & & 396147 & 251766 & 212793 & 192562 & -59204 & -23.52 \\
\hline $\begin{array}{l}\text { Industria del plástico y el } \\
\text { hule }\end{array}$ & & & 215703 & 209192 & 175768 & -39935 & -18.51 \\
\hline $\begin{array}{l}\text { Industrias de productos } \\
\text { minerales no metálicos }\end{array}$ & & & 330926 & 343679 & 297569 & -33357 & -10.08 \\
\hline $\begin{array}{l}\text { Industria de productos } \\
\text { metálicos básicos }\end{array}$ & & & 131464 & 129398 & 129639 & -1825 & -1.39 \\
\hline $\begin{array}{l}\text { Industria de fabricación } \\
\text { de productos metálicos }\end{array}$ & & & 241229 & 256452 & 222086 & -19143 & -7.94 \\
\hline $\begin{array}{l}\text { Industria de fabricación } \\
\text { de maquinaria y equipo }\end{array}$ & & & 117847 & 130454 & 129645 & 11798 & 10.01 \\
\hline $\begin{array}{l}\text { Industria de fabricación } \\
\text { de computadoras y otros } \\
\text { electrónicos }\end{array}$ & & & 312763 & 324872 & 254557 & -58206 & -18.61 \\
\hline $\begin{array}{l}\text { Industria de fabricación } \\
\text { equipo de generación } \\
\text { eléctrica y accesorios }\end{array}$ & & & 194567 & 197459 & 163334 & -31233 & -16.05 \\
\hline $\begin{array}{l}\text { Industria de fabricación } \\
\text { de equipo de transporte }\end{array}$ & & & 567426 & 604844 & 478515 & -88911 & -15.67 \\
\hline $\begin{array}{l}\text { Industria de fabricación } \\
\text { de muebles y productos } \\
\text { relacionados }\end{array}$ & & & 168953 & 166762 & 133554 & -35399 & -20.95 \\
\hline $\begin{array}{l}\text { Otras industrias manu- } \\
\text { factureras }\end{array}$ & & 1823448 & 1519404 & 1537525 & 1449478 & -69926 & -4.60 \\
\hline Suma & & & 4293456 & 4339855 & 3831633 & -461823 & -10.76 \\
\hline Resto de industrias & & & 152557 & 142856 & 147438 & -5119 & -3.36 \\
\hline
\end{tabular}

Fuente: Con base en INEGI, Sistema de Cuentas Nacionales de México (SCNM), Cuentas de Bienes y Servicios. 
Gráfica 2. Estados de México y EU incluidos en el financiamiento del BDAN

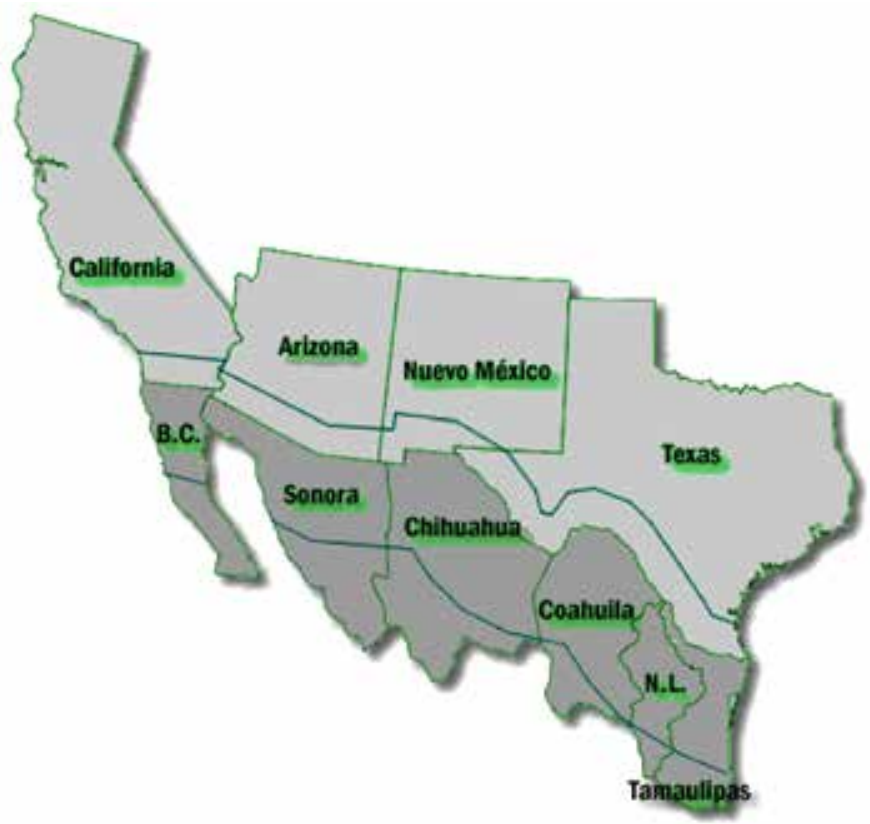

Fuente: BDAN (2016).

La lista de proyectos financiados con recursos del BDAN muestra que de los 2,617.89 millones de dólares ejercidos durante los 22 años de operación del TLCAN, 1,177.91 millones se destinaron a los estados fronterizos de EU (45 por ciento del total), en tanto que sus contrapartes del lado mexicano recibieron 1,439.98 millones ( 55 por ciento del total). Los estados más beneficiados por el lado estadounidense han sido Texas, que ha ejercido casi la mitad de los recursos asignados a ese país, y por el lado mexicano Tamaulipas, con casi un tercio del crédito asignado a México, seguido por Baja California, con la cuarta parte (cuadro 4). Los rubros de infraestructura en que se inscribe el uso de los recursos son: agua potable, saneamiento, calidad del aire, conservación de agua, drenaje pluvial, energía eólica, energía solar, infraestructura urbana básica, otra energía limpia y transporte público. 
122 ECONOMÍA TEORÍA Y PRÁCTICA • Nueva Época, número 47, julio-diciembre 2017

Cuadro 4. Financiamiento de infraestructura por estado otorgado por el BDAN hasta el 30 de septiembre de 2016 (millones de dólares)

\begin{tabular}{|c|c|c|c|c|c|c|}
\hline \multirow{2}{*}{ Estado } & \multirow{2}{*}{$\begin{array}{l}\text { Población a } \\
\text { beneficiar }\end{array}$} & \multirow{2}{*}{$\begin{array}{c}\text { Proyectos } \\
\text { totales }\end{array}$} & \multirow{2}{*}{$\begin{array}{c}\text { Costo total de } \\
\text { proyectos }\end{array}$} & \multicolumn{3}{|c|}{ Total financiamiento } \\
\hline & & & & autorizados & contratados & clereidos \\
\hline \multicolumn{7}{|l|}{ ESTADOS UNIDOS } \\
\hline Arizona & 310,121 & 20 & $\$ 364.57$ & $\$ 197.18$ & $\$ 197.18$ & $\$ 191.57$ \\
\hline California & 1.686 .358 & 25 & $1,177.48$ & 413.10 & 402.10 & 399.56 \\
\hline Nuevo Mérico & 178,061 & 11 & 78.87 & 40.21 & 40.21 & 28.70 \\
\hline Texas & $1,378,380$ & 52 & $1,530.77$ & 570.05 & 570.06 & 558.09 \\
\hline Region fronteriza & & 1 & 63.00 & 50.00 & $\cdot$ & $\cdot$ \\
\hline Subtotal EE.UU. & $3.502,920$ & 109 & $\$ 3,214.68$ & $\$ 1,270.55$ & 51.209 .55 & $\$ 1,177.91$ \\
\hline \multicolumn{7}{|l|}{ MEXICO } \\
\hline Baja Callomia & $2,840,000$ & 29 & $1,362.77$ & 376.05 & 376.06 & 360.02 \\
\hline Chihuahua & $1,703,438$ & 30 & 518.52 & 157.38 & 150.96 & 145.75 \\
\hline Coshuila & $1,063,231$ & 10 & 594.83 & 157.21 & 148.90 & 92.17 \\
\hline Nuevo León & $4,153,083$ & 10 & 871.71 & 271.36 & 202.06 & 199.60 \\
\hline Soncra & $1,310,183$ & 26 & 415.76 & 200.14 & 183.89 & 176.86 \\
\hline Tamadipas & 1.940 .435 & 20 & $1,317.50$ & 454.42 & 454.42 & 445.86 \\
\hline Regon fronteriza & 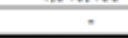 & 2 & 46.38 & 35.02 & 35.02 & 19.73 \\
\hline Subtotal Mexico & $13,010,370$ & 127 & $5,127,46$ & $1,651.58$ & 1.551 .29 & $1,439.98$ \\
\hline TOTAL & $16,358,199$ & 236 & $\$ 8,342,14$ & $\$ 2,922.13$ & $\$ 2,760.84$ & $\$ 2,617.89$ \\
\hline
\end{tabular}

Fuente: BDAN (2016).

\section{REVISIÓN EXPOST DE LAS PREVISIONES DE LOS MODELOS}

Diversas mediciones sobre el índice de CII y múltiples análisis de EGC, EP y EM elaborados en México y EU a principios de los noventa sostenían que el TLCAN en particular, aunque también otros acuerdos comerciales que México estaba firmando con el mundo, potenciarían las exportaciones del país así como el CII, el cual no sólo era muy alto ya para entonces, sino que exhibía desde 1980 tasas de crecimiento muy dinámicas. En el marco de este razonamiento, se desdeñaron las posibles consecuencias de la integración. Es decir, se asumió que, dados los altos índices de GL, las industrias de México y EU se encontraban tan estrechamente vinculadas que lo único que haría el TLCAN sería integrarlas más, por lo que no se requerirían medidas de mitigación del ajuste a nivel de rama o sector.

Asimismo, se confió excesivamente en la capacidad predictiva de los modelos de EGC, EP y EM, cuya apreciación virtualmente unánime era que el país más beneficiado de los tres en términos de dinámica exportadora, crecimiento, industrialización, desarrollo, empleo, salarios reales de trabajadores poco calificados y derramamientos tecnológicos sería México, en el que se observaba la más alta elasticidad exportaciones-empleo. En este contexto, se dio un peso muy alto al 
desmantelamiento arancelario como instrumento igualador del acceso al amplio mercado de América del Norte y se pensó que, en caso de que algunos sectores o ramas acusaran problemas de ajuste, éstos se resolverían con financiamientos disponibles a través del futuro BDAN.

Los estudios elaborados por los investigadores estadounidenses mostraron siempre dos reservas respecto a México: por una parte sugerían que el TLCAN favorecería a un número limitado de industrias nacionales, y por otra observaban que se generaría un flujo de hasta 600 mil trabajadores provenientes del campo, que el sector urbano mexicano no sería capaz de absorber y por tanto buscarían migrar hacia EU. Mientras tanto, los estudiosos mexicanos sugerían en sus modelos que prácticamente todas las ramas del sector manufacturero resultarían beneficiadas con el TLCAN, en principio porque las industrias de bienes comercializables pertenecientes a éste crecerían muy rápido, sobre todo si el cálculo se efectuaba suponiendo economías de escala, salarios reales constantes y un régimen cambiario flexible (algo que se cumplió casi completamente). Sus análisis sugerían que, dadas estas circunstancias, se impulsarían el crecimiento económico y el empleo, y sería posible que la mano de obra desplazada del campo encontrara ocupación fundamentalmente en el sector urbano.

En materia de ingresos, mientras los estudiosos estadounidenses estimaban que se mantendría la brecha salarial entre trabajadores mexicanos y estadounidenses (aproximadamente 10 a 1 en términos de dólares), sobre todo porque el TLCAN sólo beneficiaría a los menos calificados del primer país, el cual de cualquier forma recibiría más IED en términos relativos, los analistas mexicanos eran proclives a creer que los salarios ya habían tocado piso y necesariamente subirían.

En la práctica, las cosas no funcionaron así, ya que el número de empleos remunerados en el sector manufacturero en su conjunto y en las ramas que se esperaba resultaran mejor libradas de la apertura ha disminuido a partir de 2003, no obstante que en algunas de ellas las exportaciones han crecido aceleradamente, como automotriz y electrónica. Paralelamente, el crecimiento del producto ha sido apenas un punto porcentual superior al de la población, sin contar el regreso neto de migrantes provenientes de EU desde la crisis de 2008-2009. Asociado a esto, lo mismo el CII total que el CII manufacturero disminuyeron paulatinamente entre 2000 y 2010, provocando que se estancara el proceso de industrialización de México, que en gran medida depende de las inversiones y el comercio con EU. Aunque entre 2010 y 2015 dicho CI regresó a los niveles que tenía en 2000, se observó la desarticulación de muchas industrias con sus pares de EU, entre ellas la petrolera, la químico-petroquímica, la textil, la de prendas de vestir, la mueblera, la juguetera y la farmacéutica. Ello implicó no sólo una reducción de la participación de dichas industrias en el mercado estadounidense, sino la mayor presencia de los 
exportadores estadounidenses y de otros países en el mercado mexicano, con lo que los superávit de principios de los años noventa se convirtieron en déficit crecientes. Paralelamente, creció el déficit de diversos productos agropecuarios, particularmente granos y carne.

Mientras el gobierno de EU creó un subprograma para apoyar a los trabajadores desplazados por el tratado, conocido como NAFTA-TAA, en el que entre $1994 \mathrm{y}$ 2002 se hicieron elegibles 525 mil personas, muchos productores y trabajadores mexicanos parecían tener la idea de que el BDAN financiaría a las ramas y sectores más afectados por la liberación. Empero, los esfuerzos del banco se circunscribieron a apoyar proyectos de infraestructura en los estados fronterizos de México y EU, brindando entre enero de 1994 y septiembre de 2016 apoyos por 2,617.89 millones de dólares (119 mil dólares promedio por año). De éstos, más de la mitad fluyó al lado mexicano, en especial a los estados de Tamaulipas (31 por ciento del total ejercido por México) y Baja California (25 por ciento), acentuando las diferencias de desarrollo entre el norte de la república y el resto del país.

\section{Lo QUE MÉXICO YA NO PEDIRÁ SE CORRIJA DEL TLCAN}

El TLCAN no sólo dista mucho de las expectativas que generó en México si se consideran sus resultados en materia de crecimiento económico, generación de empleos y apoyo a los sectores afectados, sino también porque se incumplieron los objetivos de plena apertura que las partes asumieron al firmarlo. No obstante, las autoridades del país se han mostrado cooperativas: en particular, aceptaron ajustes trascendentales promovidos por EU, como el ASPAN, en respuesta a los ataques terroristas del 11 de septiembre de 2001, y el Proyecto de Seguridad Energética de América del Norte (PSEAN). Asimismo, han hecho eco de varias iniciativas que no llegaron a concretarse, como el Área de Libre Comercio de las Américas (ALCA) y el Acuerdo de Asociación Transpacífico (TPP).

En materia de plena apertura, los principales reclamos del gobierno y los productores nacionales se derivan de los siguientes casos:

- El mercado estadounidense del atún se ha mantenido virtualmente cerrado a los productores mexicanos, no porque atrapen delfines en el proceso de pesca, pues hace mucho que modernizaron su flota atunera, sino porque el producto es sujeto de restricciones no arancelarias en EU que tienen que ver con el etiquetado (dolphin safe), mismo que es responsabilidad de los distribuidores minoristas.

- Las autoridades mexicanas han perdido en páneles internacionales casos sonados de demandas, como el impuesto compensatorio que aplicaron durante años, por una decisión del Congreso, a las importaciones de alta fructuosa 
provenientes de aquel país, en virtud de su efecto innegable sobre los productores nacionales de azúcar. Finalmente, hubo que reintegrar a los productores estadounidenses dichos recursos para resarcir el daño.

- Contrario sensu, México ha tenido que asumir el proteccionismo estadounidense, traducido en cuotas y/o impuestos compensatorios, hacia productos como varilla de acero, aguacate, tomate rojo, fresa, melón, pepinos, lechuga, mango, caramelos, juguetes y azúcar refinada. Las acusaciones han ido desde dumping hasta contaminación (sobre todo con salmonella en las frutas y verduras) y uso de productos tóxicos en las envolturas. Incluso, como en el caso de la carne de res y de puerco, México ha enfrentado prácticas de etiquetado discriminatorio por parte de los distribuidores estadounidenses que han inducido al consumidor minorista a no comprar los productos importados; y aunque en mayo de 2015 ganó el litigio y a fines de ese mismo año los importadores acordaron retirar el etiquetado discriminatorio, los productores no han recibido los recursos por más de 700 millones de dólares que México exigió ante la Organización Mundial de Comercio (OMC) para resarcirles por el daño. Dada la vulnerabilidad de México en materia de protección no aranceleria a productos de consumo humano, no se descarta la posibilidad de que, aún dentro del tratado, EU arrecie los ataques como una estrategia de debilitamiento progresivo.

- Aunque a principios de 2015 por fin se desbloqueó el paso transfronterizo de tractocamiones nacionales hacia EU, sigue habiendo quejas por parte de las compañías mexicanas debido a las restricciones impuestas a sus unidades (revisiones exhaustivas, emisión de contaminantes, etcétera) y a los conductores (perfecto inglés, óptimo estado de salud, etcétera). Para subsanar estos problemas, las empresas optan por subcontratar dichos servicios, lo que aumenta sus costos.

- En materia de fuerza de trabajo, las restricciones a la migración aumentaron a partir de la gran recesión, las cuales se combinaron con la repatriación de connacionales, provocando un flujo neto negativo de migrantes de aproximadamente -23 mil personas por año entre 2009 y 2014 (González-Barrera, 2015).

- Finalmente, México enfrenta el descenso constante de nueva inversión estadounidense, que después de haber llegado a 16,123.8 millones de dólares en 2001 bajó a apenas 3,949 millones en 2015 (CEFP, 2016). En la actualidad, la mayor parte de la inversión proveniente de ese país tiene su origen en la reinversión de utilidades, lo que explica el estancamiento del proceso de integración de ambas economías. 
A pesar de los desacuerdos expuestos, el gobierno mexicano aclaró, en el marco de las celebraciones trilaterales por los 20 años del TLCAN, que su propósito no era renegociar el tratado, sino replantearlo.

\section{ConClusiones}

\section{¿Negociar desde cero?}

México ha propuesto ver a América del Norte como una región que debe competir con otras, particularmente la asiática, y que en las negociaciones comerciales extrarregionales se actúe de manera común frente a otros bloques reconociendo, además de la abundancia del capital y el desarrollo tecnológico de EU y Canadá, la alta competitividad de la mano de obra mexicana. Al respecto mostró extrañeza por el hecho de que, mientras ha estado dispuesto a participar con EU en diversas iniciativas de integración comercial, sobre todo enfocadas a América Latina y a Asia, dicho país lo excluyó al final de la administración de Obama, igual que a Canadá, de sus negociaciones con Europa tendientes a un eventual tratado con Europa (TLC EU-UE).

Después de conocer los puntos de vista del nuevo presidente de EU, adelantados desde su campaña electoral, México retiró de su discurso el eventual replanteamiento del TLCAN y esperó a conocer en qué medida la administración Trump buscaría honrar dos de sus principales promesas de campaña. La primera, renegociar o retirarse de aquellos acuerdos comerciales que supuestamente habían hecho que se trasladaran al extranjero, particularmente México y China, una cantidad importante de empleos. La segunda, repatriar a sus países de origen a la mayor parte de los 11.1 millones de migrantes indocumentados en EU, de los que 5.85 millones son mexicanos.

Frente a la convicción de las autoridades y empresarios mexicanos de preservar lo logrado, es decir, de mantener a México dentro de un tratado con el que han articulado una forma de producir que les permite hacer negocios, parece poco prudente volver la cara a los errores de sobreestimación de los beneficios del TLCAN previos a su puesta en marcha, y que contribuyeron a llevar las cosas a donde están hoy. Tampoco parece oportuno que intenten replantear el tratado, como pensaban hasta 2015, pues lo harían en una posición de inferioridad. Dadas las nuevas prioridades, su mejor estrategia podría ser llevar a cabo un recuento objetivo de lo que no le ha significado a México el tratado; definir en qué términos enfrentar las negociaciones con sus contrapartes, y hacer que se reevalúe la posición estratégica del país particularmente en su papel de frontera entre EU, por un lado, y América Latina y el Caribe, por otro. 
Un punto de partida es la incertidumbre del papel de Canadá en las negociaciones con EU, sobre la que parecen poco conscientes los ejecutivos y empresarios mexicanos. La inquietud surge porque quien primero estuvo dispuesto a revisar el TLCAN, ante la propuesta del candidato electo Trump, fue el primer ministro Justin Trudeau. Además, como se explicó en la sección Antecedentes, Canadá se encontraba muy cómodo con el ALCC-EU, y su ingreso tardío a las negociaciones del TLCAN se debió al temor de perder ante México un tramo de la participación de mercado y las inversiones que había obtenido de EU hasta 1990. Es bien sabido que el TLCAN es como dos acuerdos bilaterales yuxtapuestos, ya que hay una tendencia por parte de Canadá a negociar bilateralmente con EU, sin prestar mucha atención a la agenda mexicana, lo cual es comprensible si se tiene en cuenta que la integración de ambas economías es hacia la industria estadounidense y no entre ellas, excepto por el sector automotriz. Incluso es significativo que mientras el TLC EU-UE no logró concretarse en la era Obama, Justin Ttudeau sí concretó la firma de un TLC con Europa, en noviembre de 2016 (TLC C-UE). Claramente los industriales de ese país han manifestado que, si algo no funciona en las negociaciones trilaterales con EU y México, ellos darían prioridad a un acuerdo bilateral con EU, dado el tamaño y la importancia de ese mercado, y después verían si pueden hacer algo similar con México, sin descartar que se circunscriba al ámbito automotriz (Acuerdo de Complementación Económica).

Aunque el presidente electo de EU hizo explícita su intención de fijar a las empresas estadounidenses que salgan de ese país para establecerse en el extranjero aranceles de 35 por ciento cuando quieran vender sus productos en territorio estadunidense, y previamente había dicho que fijaría en general aranceles similares a ese monto a todos los productos mexicanos y chinos, sólo adoptando un régimen de total autarquía lo podría hacer con México. Esto debido a que dicho documento fija en cero los aranceles que se cobran entre sí los tres países, dado que desde hace casi una década concluyeron su desgravación arancelaria (en enero de 2008 México eliminó los aranceles que aplicaba al maíz, el frijol y la leche en polvo provenientes de Norteamérica). Debe tenerse en cuenta que, para hacer modificaciones al tratado, el presidente de EU requiere la aprobación del Congreso, pero es su prerrogativa salirse del mismo avisando con seis meses de anticipación. Además, como dijo Larry Summers en su visita a Acapulco en marzo de 2017, durante la Convención Bancaria, una eventual desaparición del TLCAN sólo serviría para allanar el camino a los exportadores chinos, que a la postre resultarían los verdaderos beneficiados.

Al salirse del TLCAN, EU debería ceñirse a los techos arancelarios registrados ante la OMC, al igual que México. Eso quiere decir que EU debería pagar al fisco mexicano 38 por ciento de impuestos para colocar en el territorio de éste sus 
productos agropecuarios y 8 por ciento para colocar sus bienes industriales. Por su parte, México sólo deberá pagar al fisco estadounidense 6 por ciento por los primeros y 2 por ciento por los segundos al colocarlos allá. Esto, combinado con un peso débil, que se depreció 58 por ciento frente al dólar estadounidense entre 2013 y 2016, hará que el superávit que ha favorecido a México desde la firma del TLCAN y que tanto escozor causa al señor Trump incluso se incremente. Además, el presidente estadounidense debe entender que dicho superávit no es sólo de México con EU, sino particularmente de las filiales estadounidenses establecidas en México con sus casas matrices establecidas en aquel país: se trata de una forma de comercio intraempresa característico de la globalización. En este marco, los japoneses aseguran que el superávit que tienen con México sería inferior si se tomara en cuenta la triangulación comercial con EU: el déficit mexicano con Japón es en parte un resultado contable del superávit mexicano con EU; y si eso es cierto, lo mismo podría estar sucediendo con Corea del Sur y China; el déficit conjunto con esos tres países registrado en 2015 (91,271 millones de dólares) representó 75 por ciento del superávit con EU (121,986 millones de dólares).

Al darse cuenta de los argumentos anteriores, el gobierno del señor Trump pareció inclinarse por la aplicación de un impuesto fronterizo denominado Border Adjustment Tax, con el que se gravarían con aproximadamente 20 por ciento las exportaciones de México a Estados Unidos, en particular las de empresas estadounidenses que hubiesen salido de ese país para establecerse en territorio mexicano. Pronto se le hizo ver que las más dañadas por la medida serían las propias empresas estadounidenses, y que el impuesto lo terminarían pagando los consumidores estadounidenses.

Si las relaciones comerciales se midieran a partir del valor agregado, los niveles de los déficit y superávit serían muy diferentes, y México seguramente tendría un superávit mucho menor con EU, pues su competitividad se basa en el costo de la mano de obra, razón que junto con otras hace que incorpore poco valor a los insumos intermedios que importa y que termina exportando como productos finales (la OCDE calcula que en 2011 el valor agregado promedio de las exportaciones mexicanas de manufacturas fue de 56.6 por ciento respecto a sus exportaciones manufactureras totales). Aunque por razones de eliminación de apoyos fiscales establecidas en la OMC México debió cambiar el nombre a la industria maquiladora de exportación desde 2006-2007, las capacidades competitivas del país se siguen desarrollando alrededor del ensamble y las actividades menos relevantes de la fragmentación de la producción, que algún país tiene que hacer. Y entre más cerca se encuentre éste del país consumidor, más coadyuva con dichas actividades a su beneficio. 
En el mismo ámbito comercial, el presidente estadounidense deberá respetar la cláusula de Nación más Favorecida, que establece que en el marco de la OMC "cualquier ventaja, favor, privilegio o inmunidad concedido por una parte contratante a un producto originario de otro país o destinado a él, será concedida inmediata e incondicionalmente a todo producto similar originario de los territorios de todas las demás partes contratantes, o a ellos destinado" (artículo 1 del GATT, en español Acuerdo General sobre Aranceles Aduaneros y Comercio).

Es claro que al esbozar su política comercial el entonces presidente electo de EU no analizó adecuadamente quiénes son los verdaderos ganadores del TLCAN. Quizás hasta principios del siglo XXI el país más beneficiado fue Canadá, pero evidentemente a raíz de la recesión de 2001-2002 las cosas cambiaron a favor del estado de Texas: sus ventas y los negocios que hace con México son de enorme dimensión. Algo similar sucede con otros estados fronterizos, en especial California y Arizona. Trump deberá pedir opinión a los gobernadores y exgobernadores de dichos estados antes de tomar decisiones comerciales como titular del gobierno federal.

Otro punto que debería indagar es la situación en que se encuentra la larga lista de industrias y sectores mexicanos perdedores del TLCAN y que ya han sido mencionados en este trabajo, desde los granos de consumo básico hasta las industrias zapatera, juguetera, textil, de la confección, farmacéutica y mueblera. Inclusive en las que todos aceptan como ganadoras, la automotriz, la de autopartes y la electrónica, entre 1998 y 2011 disminuyeron en ellas entre 15 y 19 por ciento los puestos de trabajo remunerados. De modo que más que con el comercio, la pérdida de puestos de trabajo en la industria manufacturera tiene que ver con la automatización, y eso aplica lo mismo para el Rost Belt que para México.

Sería bueno que, como aliado trilateral, el señor Trump se diera cuenta también de que México compra a EU una diversidad de productos para los que con mucha anticipación podría haber edificado capacidades productivas suficientes, como gasolinas, gas, diésel, productos químicos, productos petroquímicos y máquinas herramienta. No lo hizo en atención al principio de complementariedad y especialización que prevalece en el TLCAN y que establece que es mejor adquirir los productos en el país que exhibe las más altas economías de escala y los costos de producción más bajos. En esa idea, por la que parece racional vender a EU petróleo crudo e importarle refinados, se enmarca el Proyecto de Seguridad Energética de América del Norte (PSEAN).

Tal vez el mejor mecanismo para hacer que EU reevalúe la posición estratégica de México en el hemisferio norte de América sea evidenciando su posición geográfica como frontera entre EU, por un lado, y América Latina y el Caribe, por otro. La primera pregunta al respecto es ¿qué sucedería si después de tanto regresar población transmigratoria a sus países de origen (muchos migrantes incluso llegan 
de África diciéndose haitianos para que no se les deporte), México sencillamente los dejara pasar desde el Suchiate, el Usumacinta o cualquier otro punto de acceso? Y la segunda, aún más obvia, ¿qué sucedería si México opta por ya no ser un valladar del narcotráfico sudamericano en su tránsito hacia EU, dado el enorme costo de vidas humanas? Evidentemente habría sanciones, pero ¿cómo se contrabalancearían en la mesa de negociaciones?

Una variable adicional con que seguramente jugará México si se ve presionado por el TLCAN es la tasa de interés, que al seguirse despegando de la tasa estadounidense, como lo hizo durante todo 2016 , tal vez contribuya a que el país reciba mayores flujos de inversión en cartera, con la que buscará sustituir parte de la IED que inevitablemente se ahuyentará durante algunos años.

Colateralmente, ante la posibilidad de que la renegociación del TLCAN por parte de EU -replanteamiento por parte de México- no vaya por el camino deseado, cobra relevancia la idea de apoyar el reforzamiento del mercado interno, y en ello juega un papel crucial la recuperación del poder adquisitivo del salario. El primer paso se dio el 1 de diciembre de 2016 con el incremento al salario mínimo de 73.04 a 80.04 pesos diarios, y si se cumple la promesa de la Confederación Patronal de la República Mexicana (Coparmex) hecha en noviembre de 2016, de que en 2017 dicho salario deberá equipararse con el costo de la canasta alimentaria y no alimentaria para una persona en áreas urbanas, su nivel deberá establecerse alrededor de 96.50 pesos diarios (la proyección se hace a partir de cifras del Coneval al cierre de 2016). Ello significa que en un año el salario mínimo se incrementaría 31.7 por ciento en términos nominales y 25.4 por ciento en términos reales, algo inédito en la historia del país, aunque estaría en línea con la petición del nuevo secretario de comercio de EU, Wilbur Ross, de que México deje de competir vía bajos salarios, depreciación artificial del tipo de cambio y alto contenido de las exportaciones con insumos no elaborados en la región de América del Norte.

El alza de los salarios mínimos por sí mismo deberá provocar que se incrementen otras estructuras salariales, así sea en una proporción menor, ya que está demostrado que el salario mínimo influye en las fijaciones salariales de más de 11 millones de personas, entre formales e informales. Colateralmente, contribuiría a hacer que la participación de las remuneraciones en el PIB suba del nivel del 26 por ciento en que se situó en 2015, después de haber sostenido una declinación prácticamente continua desde 1976, cuando estaba en más de 40 por ciento.

\section{REFERENCIAS BIBLIOGRÁFICAS}

ALADI (2012), Evolución del Comercio Intraindustrial en la ALADI, ALADI/SEC, Estudio 201, Montevideo, marzo. 
Banco de Desarrollo de América del Norte (BDAN) (2015), http://www.nadbank. org/projects/proyectosactuales.asp, consultado en diciembre de 2016.

Banco Mundial (2016), Datos, en datos.bancomundial.org/indicador/NY.ADJ.NNTY.KD.ZG?locations $=\mathrm{MX}$, consultado en diciembre de 2016.

Bureau of Labor Statistics (BEA) (2016), Import/Export Price Indexes, en https:// www.bls.gov/web/ximpim/r.htm, consultado en diciembre de 2016.

Buitelaar, Rudolf y Padilla Ramón (1996), "El comercio intraindustrial de México con sus principales socios comerciales", Estudios Económicos, vol. 11, núm. 1, pp. 77-116.

Brülhart, Marius y Thorpe, Michael (2001), "Export Growth of NAFTA Members, Intraindustry Trade and Adjustment", Global Business and Economics Review, vol. 3, núm. 1, pp. 94-110.

Centro de Estudios de las Finanzas Públicas (CEFP) (2016), "Comentarios al Informe estadístico sobre el comportamiento de la inversión extranjera directa en México (enero-diciembre 2015)", Cámara de Diputados, México, marzo.

Clark, Don P.; Fullerton, Thomas M. Jr. y Burdord, Duane (2001), "Intra-indystry Trade between the United States and Mexico: 1993-1998", Estudios Económicos, vol. 16, núm. 2, pp. 163-187.

Consejo Nacional para la Evaluación de la Política Social (Coneval), "Valor mensual por persona de la línea de bienestar (canasta alimentaria más canasta no alimentaria)", en http://www.coneval.org.mx/Medicion/MP/Pagi nas/Lineas-de-bienestar-y-canasta-basica.aspx, consultado en diciembre de 2016.

Department of Labor (DOL) (1993), "A Review of the Assessments of the Likely Economic Impact of NAFTA on the United States", DOL Economic Discussion Paper 44, Washington.

Diario Oficial de la Federación (DOF) (2013), Programa para Democratizar la Productividad 2013-2018, México, 30 de agosto.

Esquivel, Gerardo (1992), "Una nota sobre el comercio intraindustrial México-Estados Unidos", Estudios Económicos, vol. 7, núm. 1.

Ethier, Wilfred J. (1982), "National and International Returns to Scale in the Modern Theory of International Trade", American Economic Review, vol. 72 .

Faustino, Horacio C. y Leitão, Nuno Carlos (2012), "Portuguese intra-industry trade and labor market adjustment costs. The SAH again", Actual Problems of Econometrics, núm. 7, pp. 494-503. 
Feenstra, Robert C. y Taylor, Alan M. (2011), Comercio Internacional, Barcelona, Reverté.

García Rocha, Adalberto; Kehoe, Timothy; Romero Tellaeche, José A. y Sobarzo, Horacio E. (1991), "Efectos del Tratado de Libre Comercio sobre la economía mexicana. Resumen de investigación", Documento de Trabajo del Centro de Estudios Económicos, El Colegio de México, noviembre.

Grubel, Herbert G. y Lloyd, Peter John (1975), Intra-Industry Trade: The Theory and Measurement of Internatioional Trade in Differentiated Products, Londres, MacMillan.

González, Jorge y Vélez, Alejandro (1991), "An empirical estimation of intra-industry trade between Mexico and the United States", San Antonio, Texas, Trinity University and St. Mary's University (mimeo).

González-Barrera, Ana (2015), "More Mexicans leaving than coming to the U. S.", Washington, PEW Research Center, noviembre.

Gutiérrez R., Roberto (2012), El Comercio intraindustrial norte-sur. Elementos teóricos y empíricos de la relación de las economías emergentes manufactureras con los países desarrollados, Saarbrücken y Madrid, AV Akademikerverlang $\mathrm{GmbH}$ y Co. KG. (2013), "Determinantes del comercio intraindustrial bilateral en economías emergentes manufactureras", Comercio Exterior, vol. 63, núm. 5, sep-oct, pp. 31-41.

Instituto Nacional de Estadística y Geografía (INEGI) (2008), La industria química en México, edición 2008, México, INEGI. (2012) Sistema de Cuentas Nacionales de México: Cuentas de Bienes y Servicios 2007-2011 (y previas hasta 1993), México. (2013), La Industria Química en México 2013, México, INEGI. (2016), Balanza comercial de México, en http://www.inegi.org.mx/est/ contenidos/proyectos/registros/economicas/comercio/default_t.aspx consultado en diciembre de 2016.

Krugman, Paul L. (1988), "La nueva teoría del comercio internacional y los países menos desarrollados", El Trimestre Económico, vol. 55, núm. 1, enero-marzo, pp. 41-66. (1991b), Una politica comercial estratégica para la nueva economía internacional, México, Fondo de Cultura Económica.

Linder, Staffan B. (1961), An Essay in Trade and Transformation, Nueva York, John Wiley and Sons. 
Lustig, Nora; Bosworth Barry P. y Lawrence, Robert Z. (eds.) (1992), North American Free Trade, Washington, The Brookings Institution.

Mattar, Jorge y Schatan, Claudia (1993), "El comercio intraindustrial e intrafirma México-Estados Unidos. Autopartes, electrónicos y petroquímicos", Comercio Exterior, febrero.

Organización para la Cooperación y el Desarrollo Económicos (OCDE) (2002), "Intra-Industry and Intra-Firm Trade and the Internationalisation of Production", OECD Economic Outlook 2002, París.

Ohlin, Bertil (1935), Interregional and International Trade, Cambridge, Harvard University Press.

Pérez Motta, Eduardo (1991), "Comercio intra-industrial 1982-1990", mimeo, Secofi, citado por Mattar y Schatan (1992).

Petróleos Mexicanos (Pemex) (2013), Anuario Estadístico 2013, México, Pemex.

Secretaría del Trabajo y Previsión Social (STPS) (2014), "Estadísticas del Sector", en www.stps.gob.mx, consultado en junio de 2016.

Sobarzo, Horacio E. (1991), "A general equilibrium analysis of the gains from trade for the Mexican economy of a North American Free Trade Agreement", en usitc (1992).

Sotomayor, Maritza (2009), "Medición del comercio intraindustrial no maquilador de México", Investigación Económica, vol. LXVIII, núm. 268, abril-junio, pp. 39-68.

(2012), "Patterns and Determinants of Intra Industry Trade for the Mexican Non-Maquiladora Manufacturing Industry", The Journal of Business Inquiry, vol. 11, núm. 1.

Stone, Joe A. y Lee, Hyun-Hoon (1995), "Determinants of Intra-Industry Trade: A Longitudinal, Cross-Country Analysis", Weltwirtschaftliches Archiv, vol. 131, núm. 1, pp. 67-84.

Tornell, Aaron (1986), "¿Es el libre comercio la mejor opción? Comercio Heckscher Ohlin versus comercio intraindustrial", El Trimestre Económico, vol. LII (3), núm. 2011, pp. 529-560.

United States International Trade Commission (USITC) (1992), Economy-Wide Modeling of the Economic Implications of a NAFTA with Mexico and a NAFTA with Canada and Mexico, USITC Publication 2508, Washington, mayo.

World Integrated Trade Solutions (wITs) (2016), UNCTAD/World Bank/UnSC/WTO/ ITC. 
